Отрасли услуг в России, в том числе и информационных, находятся на начальной стадии становления и испытывают явный недостаток собственных ресурсов для активного расширения. Интеграция в мировое хозяйственное пространство (в том числе через присоединение к ВТО) расширит возможности для использования мирового опыта, приобщения к высокой рыночной деловой культуре, перехода на новейшие технологии и методики, международные стандарты и нормы обслуживания[6].

Среди проблем России в ВТО, особое место занимает проблема кадрового характера. Это обусловлено тем, что специалистов по вопросам деятельности ВТО в России, в настоящее время, недостаточно, особенно среди молодежи. Потребность в них большая и в перспективе будет увеличиваться, в частности, в связи с созданием в будущем национальных информационно-консультационных центров в соответствии с положениями ряда соглашений ВТО и для работы в ее Секретариате.

Следовательно, необходима подготовка таких специалистов, в том числе и специалистов технического профиля, которые будут способны со знанием дела знакомить с правилами ВТО российских предпринимателей, преподавателей и студентов, экономических и отраслевых вузов, а также зарубежных представителей с выполнением этих правил в России.

$$
* * *
$$

1. Бочкарева Р. А. Креативное экономическое моделирование конкурентных преимуществ на рынке труда / Р. А. Бочкарева // Экономика образования. - 2010. - № 2. - С. 46-51.

2. Дубина И. Н. Самый важный сектор... К вопросу о соотношении понятий «креативная экономика», «инновационная экономика» и «экономика знаний» / И. Н. Дубина // Креативная экономика. - 2009. - № 6. С. 109-117.

3. Гринберг Р. С., Рубинштейн А. Я., Нуреев Р. М. Экономика общественного сектора (новая теория). Учебник. М.: Инфра-М, РИОР. 2016. 440 с.

4. Гулякин Д.В. Социально-информационная компетентность в структуре деятельности личности // Научные проблемы гуманитарных исследований. -2009. - № 12. С. 36-39.

5. Гулякин Д.В. Информационная деятельность в процессе формирования социально-информационной компетентности будущего специалиста // В мире научных открытий. 2010. № 2-2 (8). С. 19-21.

6. Вартанова Е.Л. Медиаэкономика: ключевые понятия // Вестник Московского университета, серия «Журналистика». -2002. -№ 1. -С. 17-33.

\title{
Гутрова Ю.В., Пудеева Е.А. \\ По вопросам межличностной коммуникации в сфере образования (в условиях развития цифровой образовательной среды)
}

doi: 10.18411/trnio-09-2021-43

ГБУ ДПО ЧИППКРО

(Россия, Челябинск)

\section{Аннотация}

Статья посвящена проблеме обеспечения эффективной межличностной коммуникации в сфере образования в условиях развития цифровой образовательной среды. В статье описаны приемы, технологии, способствующие установлению межличностного контакта педагога с обучающимися в цифровом пространстве, представлен алгоритм и пример разработки интерактивного инструмента профориентационного характера.

Ключевые слова: межличностная коммуникация, приемы, технологии, цифровое пространство, алгоритм, интерактивный инструмент, профориентация.

\section{Abstract}

The article is devoted to the problem of ensuring effective interpersonal communication in the field of education in the context of the development of the digital educational environment. The article describes the techniques and technologies that contribute to the establishment of 
interpersonal contact between a teacher and students in the digital space, presents an algorithm and an example of the development of an interactive tool of a career-oriented nature.

Keywords: interpersonal communication, techniques, technologies, digital space, algorithm, interactive tool, career guidance.

В современном обществе происходят глобальные социокультурные и информационно-коммуникационные трансформации, которые актуализируют вопросы коммуникативного взаимодействия, сотрудничества, взаимопонимания. Система образования претерпевает качественные изменения: гуманизация, цифровая трансформация, новые требования к личности и роли педагога в образовательном процессе. Современный учитель должен быть готов и способен работать в новых условиях, предполагающих использование коммуникационных технологий и реализацию коммуникативных умений в рамках новой цифровой образовательной среды.

В настоящий момент в нашей стране идет реализация национального проекта «Образование» (2018-2024 г.), важной частью которого является проект «Цифровая образовательная среда». Основная задача проекта заключается в создании к 2024 году современной и безопасной цифровой образовательной среды, позволяющей существенно расширить доступ обучающихся к качественным программам обучения, при этом данное решение не подразумевает ухода от традиционных занятий в школах. Цифровая образовательная среда создает условия в традиционной классно-урочной системе обучения использовать возможности электронного обучения, дистанционных образовательных технологий, электронные информационные и образовательные ресурсы, в результате чего, по мнению И.Е. Жидковой, «происходит оптимизация учебной среды за счет доступного учащимся формата цифровых образовательных ресурсов» [1, с. 167].

Цифровые образовательные ресурсы применяются педагогами не только в образовательном процессе, но и во внеклассной работе, внеурочной деятельности, в дополнительном образовании.

Спектр цифровых инструментов достаточно широк: мультимедийные презентации, видео и аудиоматериалы, электронные книги и журналы, развивающие игры, онлайн-уроки, видеолекции, виртуальные экскурсии, интернет проекты и др. Функционируют и интернетплатформы, порталы, позволяющие смоделировать онлайн-уроки, задания, квесты, практические и лабораторные работы, модификационные игры и прочее.

Мы предлагаем рассмотреть возможность разработки и применения альтернативного варианта цифровых инструментов (продуктов) на примере интерактивного портфолио «Я и моя будущая профессия» (автор-разработчик Пудеева Е.А.).

Минпросвещение ориентирует педагогическое сообщество развивать направление профориентации. Федеральный проект «Успех каждого ребенка» нацеливает на развитие профессиональных компетенций обучающихся. Делать осознанный выбор будущей профессии - одно из требований ФГОС к результатам освоения программ основного общего и среднего общего образования. Таким образом, интерактивное портфолио «Я и моя будущая профессия» и подобные цифровые продукты - актуальные современные педагогические инструменты, позволяющие аккумулировать информацию, автоматизировать контроль и создать условия для развития уникальности обучающихся, их творческого и интеллектуального потенциала, ключевых компетенций (Soft skills, Hard skills).

Основа интерактивного портфолио «Я и моя будущая профессия» создана по принципу разработки интерактивного учебного пособия (в открытом доступе в сети интернет videouroki).

Ниже представлена информация по технической части интерактивного инструмента.

Для разработки интерактивного инструмента (интерактивное учебное пособие, портфолио и др.) рекомендуем использовать программы, например, Word, PDF, PowerPoint или личный сайт, главное условие - возможность применить гиперссылки. 
Преимущество интерактивного инструментария в неограниченном объеме содержания (контента), поэтому необходимо предварительно подготовить (аккумулировать) весь материал, который будет использоваться в работе: текстовая информация, фото, аудио и видео материалы, презентации, тесты, статьи, рисунки и пр., сохранить данные материалы в папке на рабочем столе компьютера или, в случае дистанционного пользования - в облачном хранилище (Google Drive, Яндекс.Диск, Облако Mail.ru, MEGA и др.).

Следует отметить, что облачное хранилище Google Drive имеет большие возможности по сравнению с другими, и, что особенно важно, предоставляет одновременный доступ сразу нескольким участникам (обучающимся, педагогу, родителям и др.) для работы с одним документом.

Заголовки, подзаголовки разделов интерактивного инструмента после введения текста в программе Word появятся в разделе «Область навигации» (верхняя панель программы «Командная строка» - вкладка «Вид» - группа «Показ» - вкладка «Область навигации»), кроме того, навигация упрощает работу с интерактивным инструментом. Группа «Стили» на командной строке (вкладка «Главное») задает стиль всего документа, его заголовков и подзаголовков.

Знакомство с дополнительной информацией осуществляется путем вставки в текстовый документ гиперссылок (правая кнопка мыши - вкладка «Гиперссылка» «Текущая папка» - выбор нужного контента (статьи, презентации, рисунка и пр.), который предварительно был собран в текущую папку). Если папка с дополнительной информацией находится в облачном хранилище, после наведения курсора на нужный файл следует нажать правую кнопку мыши и выбрать вкладку «поделиться» - скопировать ссылку и вставить в документ. Переход по гиперссылке осуществляется нажатием на клавиатуре клавиш «CtrI» и «Enter».

Введение интерактивного портфолио «Я и моя будущая профессия» - своего рода, гид-путеводитель для обучающихся в составлении собственного портфолио, представлено в виде обращения, знакомит пользователя с понятийным аппаратом, правилами работы с портфолио.

Содержательная часть интерактивного портфолио «Я и моя будущая профессия» состоит 3 разделов.

Первый раздел «Мой портрет» включает 4 формы (на выбор) самопрезентации, автобиографию и образец для заполнения.

Актуальные вопросы для данного раздела: кто я? Как я могу рассказать о себе другим?

Второй раздел «Карта личностного роста» включает индивидуальный образовательный маршрут, психологические онлайн-тесты, арт-терапевтические упражнения, тематические видеоматериалы, коучинговые технологии, коучинговые вопросы, документы: характеристики, отзывы, грамоты, дипломы за участие в конкурсах, смотрах, олимпиадах разного уровня, творческие работы и др. Главное назначение этого раздела - самопознание. Актуальные вопросы для данного раздела: чем я отличаюсь от других и куда мне расти дальше?

Третий раздел «Мои профессиональные предпочтения» знакомит обучающихся с атласом новых профессий XXI века, формулой выбора профессии, особенностями заполнения резюме, по гиперссылкам доступны виртуальные профориентационные экскурсии, профориентационные тесты и др. Актуальный вопрос для данного раздела: какая профессия мне подходит?

Практическая значимость интерактивного портфолио для педагога:

- является одной из современных форм взаимодействия с обучающимися и родителями (законными представителями);

- является средством повышения профессионального мастерства в вопросах профориентации обучающихся; 
- способствует осуществлению всестороннего анализа результатов деятельности обучающегося;

- мобильность и технологичность в использовании в сравнении с традиционной формой портфолио;

является инструментом мотивации обучающихся для продуктивной учебной деятельности, качественных и количественных личных достижений;

- обеспечивает «включение ребенка в школьную жизнь» и формирование активной жизненной позиции.

Практическая значимость интерактивного портфолио для обучающегося:

- обеспечивает «включение ребенка в школьную жизнь» и формирование активной жизненной позиции;

- является средством самопознания, активизации внутренних ресурсов, потенциала, повышения самооценки обучающегося;

- содействует осознанному выбору будущей профессии;

- развивает ключевые компетенции (Soft skills, Hard skills);

- помогает управлять процессами самоконтроля, самоанализа и саморазвития;

- результатом ведения портфолио является наличие первичного профессионального плана с учетом индивидуальных особенностей и способностей обучающегося.

Интерактивные инструменты, в большинстве случаев, имеют дистанционный формат, и, если для подростков - это привычная среда (общение в социальных сетях, мессенджерах: WhatsApp, Vider, Telegram и др.), то для педагога - актуальная задача по выстраиванию эффективной коммуникации, обусловленная:

- отсутствием личного контакта;

- новой формой общения;

- ограниченностью в выражении эмоций, а значит непониманием и отсутствием умений своевременно реагировать на потребности обучающихся.

Педагогическая коммуникация в условиях цифровой среды претерпевает значительные изменения. Коммуникативные ресурсы традиционной образовательной среды (диалогические линейные коммуникации, замкнутые на учителе) обогащаются гибкими нелинейными коммуникациями в цифровой среде, роль обучающихся в которых значительно возрастает.

В последние годы появился целый ряд работ (Л.В. Бендова, Е.Л. Гаврилова, Е.С. Комраков, Т.А. Сергеева и др.), в которых обсуждается проблема коммуникации участников образовательного процесса в цифровом пространстве. Исследователи рассматривают различные стороны межличностной коммуникации в образовательном пространстве, подчеркивая специфические особенности изучаемого явления. В процессе коммуникации с обучающимися учителю необходимо обращать внимание на степень адаптивности своей речи. Адаптивность речи, по мнению С.В. Тетиной, должна достигаться «не за счёт чрезмерного упрощения, а путём использования коммуникативных приёмов: повторов, перифраза, риторических средств» [6, с. 167].

В современной науке накоплен большой теоретический багаж, связанный с осмыслением феномена «межличностная коммуникация», несмотря на то, что в научный дискурс понятие вошло сравнительно недавно, в 70-80 гг. XX в., с появлением в обществе интереса к проблеме информации и коммуникации.

Коммуникация как термин появляется в научной литературе только в начале XX в. Автор этого термина, американский социолог Чарльз Кули, определил коммуникацию как «механизм, посредством которого становится возможным существование и развитие человеческих отношений - все символы разума вместе со способами их передачи в пространстве и сохранения во времени» [2, с. 167]. 
Термин «межличностная коммуникация» рассматривается нами как «осуществляемое с помощью средств речевого и неречевого воздействия взаимодействие между людьми, в результате которого возникают психологический контакт и определенные отношения между участниками общения» [3, с. 3$]$.

Анализ научной литературы позволяет выделить смежные дефиниции. Так, понятие «межличностный контакт» (от лат. contactus - касание) становится одним из инструментов исследования проблемы возникновения условий общения, поскольку обозначает то, что люди находятся в пределах доступности для восприятия друг друга, при этом направлены (физически и психологически) друг на друга. Тем самым они не только признают сам факт существования друг друга, но и вступают во взаимодействие, создавая условия для передачи информации по каналам связи. В соответствии с видом контакта (деловой, душевный) складываются отношения между людьми.

Понятие «межличностная коммуникация» направлено на анализ способов обмена сообщениями между партнерами, их приема и переработки.

Понятие «межличностное взаимодействие» подчеркивает активность общающихся, позволяя более пристально исследовать формы и виды индивидуальных действий, приводящих к взаимным изменениям поведения, деятельности, отношений и установок.

Хотелось бы возразить исследователю И.Н. Розиной, которая при описании педагогической коммуникации в цифровой образовательной среде ведущую роль отдает преподавателю. В исследовании, посвященном изучению педагогической коммуникации в электронной среде, автор определяет доминирующую роль преподавателю, а именно «инициатором и руководителем процесса коммуникации в обеих средах обучения традиционно является преподаватель [5, С. 99]. В противовес данному мнению отметим, что цифровая трансформация образования предполагает образовательный процесс, в котором учитываются как социально заданные цели обучения (образовательный стандарт), так и самостоятельно поставленные обучающимися образовательные цели, в связи с чем, инициатором выступает именно обучающийся, его познавательный и исследовательский интерес является движущей силой для возникновения межличностной коммуникации «учитель-обучающийся». Цифровые технологии создают условия для решения этой задачи за счет совершенствования средств планирования и организации образовательного процесса, широкого использования активных методов обучения и перехода к персонализированной, результативной организации образовательного процесса.

Основополагающей особенностью информатизации образования, по словам директора Института информатизации образования Российской академии образования профессора Роберт И.В., является «изменение парадигмы учебного информационного взаимодействия между обучающим, обучающимся (обучающимися) и интерактивным источником образовательного информационного ресурса, обладающего дидактическими возможностями информационных и коммуникационных технологий: реализация незамедлительной обратной связи между пользователем и интерактивным источником учебной информации (интерактивный диалог); представление по запросу пользователя любых объемов аудиовизуальной информации; автоматизация процессов поиска, обработки, формализации, продуцирования, использования, распространения учебной информации; моделирование, виртуальное представление на экране изучаемых объектов, их отношений, процессов, ситуаций; управление виртуально представленными на экране объектами, процессами, ситуациями» [4, С. 10]. Данное обстоятельство определяет трехкомпонентный состав образовательного взаимодействия, а именно включение средств ИКТ в традиционное двухкомпонентное взаимодействие: обучающийся-обучающий.

Рассмотрим приемы, способствующие установлению межличностного контакта в цифровом пространстве в контексте учитель-ученик.

Первый прием - это адаптация учебного материала к аудитории обучающихся. В данном случае под адаптацией материала мы понимаем «активный процесс вербального и визуального приспособления материала для представления конкретной аудитории 
обучающихся». Для решения данной задачи важно установить психологический контакт с аудиторией обучающихся в первые 40 секунд. В цифровом пространстве это сделать гораздо сложнее, чем при живом контакте с коллективом, когда Вас видят, и Вы можете использовать широкий арсенал выразительных невербальных средств коммуникации. Например, доброжелательный взгляд, располагающая улыбка, открытая поза помогают создать доверительные отношения и усилить восприятие учебной информации. Напомним, что около 67\% информации человек получает по невербальному каналу. В цифровом образовательном контенте перцептивная сторона общения представлена не в полной мере. Именно поэтому учителю рекомендуется обратить внимание на усиление взаимопонимания между участниками образовательного процесса, показать, что учитель и обучающиеся испытывают похожие чувства, например, любознательность, открытость новому знанию, познавательную интригу. Возможно, мы имеем общий опыт в проведении исследования, неоднозначные с точки зрения науки, полученные результаты и т.д. В случае если гипотеза не подтвердилась, либо эксперимент не удался, отрицательные чувства, озвученные аудитории, также будут способствовать объединению участников образовательного процесса.

Один из самых простых способов достичь быстрого взаимопонимания с аудиторией это использовать личное местоимение. Рекомендуем чаще употреблять в обращении к аудитории слова «вы», «нам», «мы», «наше». Таким образом, учитель в цифровом пространстве «персонифицирует информацию», показывает обучающимся, что он говорит именно с данной группой обучающихся. Приведем конкретные примеры построения речевых высказываний учителя: «Когда Вы слышите понятие «скорость», какие образы у вас возникают?» «Если вы подумаете о силе притяжения, то вы возможно спросите себя - как это действует лично на меня, и как я это ощущаю?»

Второй прием установления межличностного контакта в цифровом образовательном пространстве состоит в том, чтобы ставить активизировать внимание обучающихся через постановку риторических вопросов. Например, как на Вас влияет процесс глобального потепления на планете? Каким образом негативная информация в СМИ влияет на поведение членов вашей семьи?»

Исследования в сфере социальной психологии подтверждают факт эффективного влияния риторических вопросов на познавательную активность обучающихся. Для усиления эффекта риторического вопроса на аудиторию, рекомендуется учителю в цифровом контенте вывести вопрос в презентации на отдельную страницу. Воздействие на обучающихся можно усилить вербальными средствами, а именно, искренностью и непринужденностью в постановке вопроса.

Третий прием установления межличностного контакта с аудиторией в цифровой образовательной среде состоит в том, чтобы учитель делился с обучающимися общими переживаниями. Например, знакомство с художественным произведением «Денискины рассказы» Виктора Драгунского: «Ребята, прочтение данного художественного отрывка позволило мне вспомнить мое детство, как я был маленьким и не всегда хотел делать домашнее задание...я помню, как я любил запускать воздушного змея......а как я был огорчен и рассержен, когда я не выучил урок из-за поломки воздушного змея, и потерпел фиаско у доски». Высказывание чувств учителем сближает с обучающимися, создает доверительную атмосферу, усиливает эмоциональное воздействие учебной информации, следовательно, положительно воздействует на учебную мотивацию и качество обучения.

$$
* * *
$$

1. Жидкова, И.Е. Информационно-коммуникационные технологии в современном иноязычном образовании / И.Е. Жидкова // Интеграция методической (научно-методической) работы и системы повышения квалификации кадров: Материалы ХІХ Международной научно-практической конференции, Москва Челябинск, 20 апреля 2018 года / Ответственный редактор Д.Ф. Ильясов. - Москва - Челябинск: Челябинский институт переподготовки и повышения квалификации работников образования, 2018. - С. 164168. 
2. Кули Ч. Общественная организация. Тексты по истории социологии ХІХ-ХХ веков. - М.: Наука, 1994. C.167-169.

3. Куницына В.Н., Казаринова Н.В., Погольша В.М. Межличностное общение. Учебник для вузов. - СПб.: Питер, $2001-544$ c.

4. Роберт И.В. Теория и методика информатизации образования (психолого-педагогический и технологический аспекты) [Электронный ресурс] / И.В. Роберт. - Эл. изд.-М. : БИНОМ. Лаборатория знаний, 2014.—398 с.: ил. - (Информатизация образования).

5. Розина, И.Н. Педагогическая коммуникация в электронной среде / И.Н. Розина // Известия вузов. Северокавказский регион. Общественные науки. 2004. № 2. - С. 97-99.

6. Тетина, С.В. Методическая грамотность как часть профессиональной компетентности учителя иностранного языка / С.В. Тетина // Научное обеспечение системы повышения квалификации кадров: научнотеоретический журнал. - 2016. - №3 (28). - С.164 - 169.

\section{Загоровская Н.В. \\ История изучения подвижных игр в русской педагогической мысли}

Российский государственный университет физической культуры, спорта, молодежи и туризма

(Россия, Москва)

doi: 10.18411/trnio-09-2021-44

\section{Аннотация}

Подвижные игры являются средством физического воспитания с древних времен на различных возрастных этапах развития человека. В статье рассматриваются основные вехи изучения дисциплины «Подвижные игры» в рамках педагогики, обозначаются перспективы использования подвижной игры как воспитательного и образовательного метода в условиях современного общества.

Ключевые слова: игра, подвижные игры, педагогика, история подвижных игр.

\section{Abstract}

Outdoor games have been a means of physical education since ancient times at various age stages of human development. The article discusses the main milestones of the discipline "Outdoor games" study in the framework of pedagogy, outlines the prospects for the use of outdoor games as an educational method in the conditions of modern society.

Keywords: game, outdoor games, pedagogy, history of outdoor games.

С древних времен игра использовалась как средство воспитания детей и педагогическая модель для обучения человека необходимым для выживания и развития навыкам: общению, физической подготовке, охоте, ремесленному делу. Исследование игры позволяет понять механизмы взаимодействия людей более полно. Именно с точки зрения средства воспитания эстетического и нравственного на игру смотрели античные философы: Платон подчеркивал, что ее следует поддерживать в деятельности ребенка, потому что она подражание действительности, а Аристотель видел в игре гармонию души и тела, она существует для удовольствия и отдыха [1, с.376-644]. Игра у Платона не обладает истиной, но ее можно с помощью игры познать [13, с.4]. Кроме того, философ выделяет в игре несколько особенностей: она непредсказуема, несерьезна, свободна, призвана дарить удовольствие. В жизни древнего мира игры существовали в форме воспитательной и обрядовой. Причем у римлян в играх обязательно присутствовал компонент пользы, в своем трактате «Об образовании оратора» Марк Фабий Квинтилиан перечисляет игры, необходимые для обучения детей [6].

В Средневековье игра наиболее полно воплотилась в религиозных культах и смеховой культуре. Она, несмотря на все запреты, описанные, например, в трудах Аврелия Августина, продолжала существовать и в церковной среде: ритмомахия, подвижные упражнения, игры, входящие в учебную программу, занятия футболом и теннисом. В эпоху Возрождения взгляд 